\title{
UM PERCURSO TEÓRICO-METODOLÓGICO PARA O ESTUDO DE CONSTELAÇÕES DE GÊNEROS
}

Júlio César Araújo ${ }^{1}$

Resumo: Neste ensaio, proponho um percurso teórico-metodológico que permita fundamentar uma possivel reflexão sobre o fenômeno de agrupamentos de gêneros discursivos. Para tanto, empreendo uma análise dos argumentos de Marcuschi (2000) e de Bakbtin ([1929] 2002) acerca do agrupamento de gêneros. Embora haja discrepâncias entre uma e outra proposta de conceber uma constelação de gêneros, é possivel estabelecer um ponto consensual entre esses estudiosos, na medida em que ambos salientam as tendências dos gêneros às variações e às transmutações. Os efeitos dessa análise permitem a conclusão de que um estudo que queira empreender a caracterização de uma constelação de gêneros deve se estruturar a partir de três eixos temáticos fundamentais: a(s) esfera (s) de comunicação em que tais gêneros se ambientam; os rastros deixados durante o seu processo de formação e os propósitos comunicativos atendidos por cada gênero dentro da constelação.

Palavras-chave: Constelação de gêneros. Esfera de comunicação. Transmutação. Propósito comunicativo.

\section{INTRODUÇÃO}

"o que conta mesmo em pesquisa científica é a construção do objeto. Em geral, essa construção não é algo que aconteça de uma hora para outra ou sem grandes esforços, não é um plano que se desenhe antecipadamente, à maneira de um engenheiro: é um trabalho de grande fôlego, que se realiza pouco a pouco, por retoques sucessivos, por toda uma série de correções e emendas" (BOURDIEU, 2007, p. 27)

Quaisquer que sejam as categorias criadas no labor acadêmico para dar conta de um objeto investigado, elas são apenas isto: categorias, e, nesse sentido, não mostram exatamente a realidade, mas um modo de olhar e de entender a realidade empírica pautado por um projeto de pesquisa cuidadosamente planejado pelo estudioso. Contudo, afirmar que as categorias elaboradas não são a realidade empírica em si, mas apenas estratégias acadêmicas arrazoadas para construir compreensões

\footnotetext{
${ }^{1}$ Professor do Programa de Pós-Graduação em Linguística da UFC, doutor em Linguística. Email: araujo@ufc.br.
} 
acerca de um objeto, não significa, de modo algum, afiançar que os dados sejam falaciosos.

Mas o que se quer dizer quando, no contexto da pesquisa acadêmica, usamos a palavra categoria? Marx ([1867] 1983, p. 229) diz que "as categorias expressam aspectos fundamentais das relações dos homens entre si e com a natureza e são construídas através do desenvolvimento e da prática social". Cheptulin (1982, p. 5) faz eco a essa acepção ao explicar que "a definição das categorias, de seu lugar e de seu papel, no desenvolvimento do conhecimento, está diretamente ligada à resolução do problema da correlação entre o particular e o geral na realidade objetiva e na consciência". Seja como for, percebemos que as categorias são formas de intelecção sobre o que seriam "leis universais".

É importante frisar que há, pelo menos, duas maneiras de compreender o que se quer dizer quando usamos a palavra categoria. Uma delas diz respeito à organização dos dados de uma pesquisa em conjuntos pelo pesquisador, cujos critérios perpassam por alguns aspectos que os irmanam em pequenos subgrupos. Nesse sentido, os dados gerados em um processo investigativo suscitam as categorias de análise e um pesquisador contumaz passa a organizar seus dados pelo que eles revelam acerca do objeto que observa. $\mathrm{O}$ outro sentido que pode ser atribuído à palavra categoria está adstrito à construção de uma noção teórica a que as categorias de análise são submetidas. Nesse sentido, os conceitos de gênero do discurso, de língua, de interação são exemplos de categorias teóricas que são construídas pelos pesquisadores. As duas acepções para o termo categoria são legítimas e é a isso que se chama de pesquisa acadêmica. Mas é com o segundo sentido da palavra categoria que trabalharei no presente ensaio.

Essa escolha se justifica porque determinados fenômenos empíricos de linguagem atraem muitos olhares e, em função disso, suscitam muitas categorias que, por vezes, embaçam a lente da lupa. Gêneros do discurso, indubitavelmente, é um desses fenômenos humanos para o qual os pesquisadores da linguagem se voltam desde tempos imemoriais. Basta que se recorde aqui, entre outras possibilidades, de Aristóteles e sua Poética, para ficar apenas com um dos exemplos mais eloquentes da literatura clássica. 
Se a categoria gêneros do discurso em si já se mostra como um terreno movediço e, por isso mesmo, instigante, o que dizer de mais uma elaboração humana para se referir a um grupo especial de gêneros? $\mathrm{Na}$ linha de pensamento tecida aqui, seria ingênuo afirmar que os agrupamentos de gêneros do discurso são um fenômeno de linguagem, no mínimo, curioso e que, por isso, deve ser mais investigado. $\mathrm{Na}$ realidade, não são os gêneros em si que se agrupam, como se eles fossem entidades vivas a se movimentar à revelia dos sujeitos de linguagem. Assim, afirmar que os gêneros do discurso se congregam por meio de determinados traços é assumir que elaboramos categorias para agrupálos, pois eles não são seres vivos, mas ferramentas semióticas criadas pelo homem como estratégia de organização social.

O objeto de estudo que se deixa entrever até aqui e que será discutido neste texto poderia ser denominado constelação de gêneros ${ }^{2} \mathrm{e}$, nesse sentido, para retornar a Marx ([1867] 1983, p. 229), é possível afirmar que esta é uma categoria que serve para expressar "aspectos fundamentais das relações dos homens" com os textos e a sociedade. Mas agrupar gêneros como estratégia de estudo para entender melhor a complexidade das práticas de linguagem não é algo tão recente como se queira pensar, pois Bakhtin ([1929] 2002), no início do século XX, e Marcuschi (2000), no final do mesmo século, já trabalhavam com esse tema de pesquisa ${ }^{3}$. E é exatamente por essa senda que pretendo seguir neste trabalho, a fim de examinar as concepções desses dois autores com o objetivo de contribuir com a discussão sobre o conceito e a metodologia de estudo das constelações de gêneros.

As informações deste ensaio, portanto, estão distribuídas na seguinte ordem. Em primeiro lugar, examino um trabalho de Marcuschi

\footnotetext{
${ }^{2}$ Vale a pena ler os trabalhos de Bhatia (1997; 1993; 1999); Marcuschi (2000; 2004); Swales (2004); Araújo (2004; 2006); Bezerra (2006) e Lopes (2008). Todos esses autores discutiram sobre constelação/colônia de gêneros, registrando sua compreensão por meio de categorias, as quais revelam a maneira de olhar para o objeto.

${ }_{3}^{3}$ Para outros estudos sobre o tema, conferir os trabalhos de Bhatia (1993; 1997; 1999; 2001; 2004), Swales (2004) e Bezerra (2011).
}

ARAÚJO - Um percurso teórico-metodológico... 
$(2000)^{4}$ sobre o fenômeno de agrupamento de gêneros. Nesse trabalho, Marcuschi (2000, p. 14), em relação à atividade de classificação dos textos, diz que "a diversidade de formatos pode ocorrer com [muitos] gêneros que apresentam formas de realização variadas" (grifos meus). Para ele, "os gêneros podem ter realizações textuais tão diversas a ponto de não sabermos se estamos no mesmo gênero". É nesse contexto que o autor vai gestando uma noção de constelação de gêneros que, na seção de considerações finais, será comparada com a de Bakhtin para, desse exercício comparativo, deixarmos nossa colaboração acerca do tema constelação de gêneros.

Em segundo lugar, será mostrada uma concepção clássica sobre o agrupamento de gêneros por meio de um trabalho seminal de Bakhtin ([1929] 2002). Ao estudar a obra dostoievskiana, o autor russo defende o surgimento de uma variante do gênero romance. Embora sua análise, nesse caso específico, não tenha tido a intenção de estudar o conceito de constelação de gêneros e se circunscreva a um gênero literário, é relevante apresentá-la e discuti-la aqui, pois acredito que seus estudos relativos à poética de Dostoiévski possam lançar luzes nas pesquisas que se interessam em analisar os agrupamentos de gêneros 5 .

${ }^{4}$ É válida a ressalva de que a noção de constelação de gêneros, proposta de maneira ainda preliminar por Marcuschi (2000), não foi retomada pelo autor em outros trabalhos. O texto aqui citado é um produto inacabado e, mesmo assim, circulou (e ainda circula) muito pelo país sem ter sido publicado. Sua generosidade imensa o fez distribuir por e-mail para muitas pessoas a fim de poder suscitar trocas e discussões sobre várias categorias teóricas acerca dos gêneros, sendo constelação uma delas. Mesmo não tendo sido concluído pelo autor, o texto revela ideias sobre constelação de gêneros que são seminais e inspiradoras para que tentemos avançar na discussão desse tema. Com a discussão que farei nesta seção, não entenda o leitor que estou a dizer que Marcuschi se furtou à responsabilidade de expor suas categorias com clareza, pois se sabe que os gêneros do discurso não são um objeto de fácil manejo e tudo o que se fizer para seu estudo será sempre resultado de um grande esforço intelectual para dar conta de algo que é constitutivo do próprio objeto: a fluidez. Tenho a absoluta certeza de que, se pudesse, Marcuschi teria muito a dizer e nos ensinar sobre esse conceito ainda muito abstruso.

${ }^{5}$ Duas são as razões que me levam a acreditar nessa possibilidade. A primeira delas é relativa ao fato de o romance admitir variedades, o que sugere que esse gênero tem uma organização constelar. A segunda razão diz respeito a uma característica bastante especial do romance, que é a de tal gênero possuir um profundo poder absortivo, já que pode transmutar gêneros de outras esferas, como a carta e a conversa cotidiana (cf. BAKHTIN[1953] 2000, p. 281). Como veremos, a transmutação é uma categoria cara à noção de constelação de gêneros que pretendo apresentar aqui. 


\section{CONSTELAÇÃO DE GÊNEROS EM MARCUSCHI}

Segundo as reflexões desenvolvidas por Marcuschi (2000), a carta, a entrevista e a receita seriam exemplos de práticas de linguagem complexas, pois todas se realizam de muitos modos. Como ele observa, todas as atualizações da carta, da entrevista e da receita se apresentam sob variadas formas, embora, pondera o autor, haja sempre um aspecto que nos permite perceber que um determinado gênero seja uma receita, e não, por exemplo, um conto. Não obstante isso, considero curiosa a indagação que ele faz diante da aula:

Tome-se o caso da "aula". Como caracterizá-la? Trata-se de um gênero textual ou de uma constelação? $\mathrm{Na}$ realidade, pode-se dizer que a aula não é um gênero em termos técnicos, pois podemos ter aulas de vários formatos (MARCUSCHI, 2000, p. 16 , grifos em negrito meus).

A resposta dada, "em termos técnicos", é a de que a "aula não é um gênero" porque esta se atualiza em diferentes "formatos" (aulas expositivas, aulas participativas, aulas de seminários, etc.). Marcuschi, entretanto, não esclarece os critérios utilizados para sustentar essa decisão, deixando um problema a ser resolvido. Também não esclarece o que entende pelas expressões forma e formato que aparecem em seu texto. Ademais, basta que se pense na carta, na receita e na entrevista para a verificação do mesmo fenômeno da aula.

Ao tratar da carta, Marcuschi (2000, p. 14), defende que nela se encontra "um grande número de gêneros que se situam numa constelação" (grifo meu). Para fins de ilustração, o pesquisador cita os vários "formatos" que a carta pode assumir. Assim, segundo sua visão, existem os seguintes gêneros de carta: "carta pessoal, carta aberta, carta comercial, carta convite, carta do leitor, carta-resposta, carta circular, carta anônima e carta precatória".

Se cotejarmos o raciocínio desse autor para explicar a aula e a carta, não fica, portanto, claro qual seja o seu eixo definidor da constelação, pois ao mesmo tempo em que afirma que a carta é uma 
constelação de gêneros devido aos vários "formatos" que ela assume, não estende essa afirmação à aula. Além disso, é fácil perceber que o que seriam subgêneros para Bhatia $(1997)^{6}$ parece estar associado ao que Marcuschi designa gênero, já que, segundo o último, a carta abriga "um grande número de gêneros que se situam numa constelação" (MARCUSCHI, 2000, p. 14). No entanto, cada carta dessas, conforme a visão bhatiana de constelação, seria um subgênero da carta, uma vez que é possível vislumbrar alterações sutis no propósito comunicativo. Sendo assim, a noção de constelação de Marcuschi aponta para o fato de que um gênero pode conter vários eventos ${ }^{7}$ comunicativos (subgêneros?), realizando-se sob vários "formatos". Marcuschi acrescenta, ainda, que os eventos "sempre estarão subordinados a algum gênero" (2000, p. 14), logo parece haver uma organização hierárquica na definição de constelação que propõe.

Utilizando a aula como um exemplo do que designa "suporte sociocognitivo", Marcuschi (2000, p. 18) argumenta que, pelo fato de a aula ser um evento que se realiza em diferentes atividades (aulas expositivas, aulas de seminários, aulas participativas, etc.), ela não se configura como um gênero. Ao contrário, a carta, ainda que apresente (assim como a aula) vários "formatos", é vista como evento e gênero, simultaneamente. Como se vê, a questão não fica resolvida e parece se agravar ainda mais porque, em uma outra passagem do mesmo texto, a aula é elencada entre os gêneros cuja "forma textual [é] estabilizada" (MARCUSCHI, 2000, p. 19).

\footnotetext{
${ }^{6} \mathrm{Em}$ outros trabalhos, discuti sobre a noção bhatiana de constelação de gêneros (ARAÚJO, 2004; 2006). Por essa razão, no presente trabalho, limito-me a discutir o conceito de constelação de gêneros por meio de Marcuschi (2000) e Bakhtin ([1929] 2002).

${ }^{7}$ Esta noção de evento também não é consensual entre os autores. Swales e Bhatia, no conjunto de suas obras, afirmam que um gênero é um evento comunicativo. Biasi-Rodrigues (1998, p. 13) diz que para cada evento comunicativo há um gênero adequado, portanto, evento, na perspectiva de Biasi-Rodrigues, parece equivaler à noção bakhtiniana de cena enunciativa. Marcuschi (2000, p. 16), por seu turno, pressupõe não haver relação biunívoca entre evento e gênero, "pois é possível que um dado evento seja uma espécie de suporte e não necessariamente um gênero". O evento, segundo demonstra o autor, "é toda e qualquer manifestação linguística oral ou escrita comunicativa e situada" (p. 21), e gênero "é uma ocorrência textual que permite uma classificação por gêneros" (p. 21). Mas o que seria uma classificação por gêneros? A ideia defendida por Marcuschi é a de que todo e qualquer gênero é, também, um evento, no entanto, o contrário nem sempre é possível, isto é, "nem todo evento constitui um gênero" (p. 21).
} 
Similar é o caso da entrevista, a qual é vista como uma "constelação de eventos" (MARCUSCHI, 2000, p. 111). Nesse contexto, o autor chega a postular a possibilidade de "chamar esses eventos de subgêneros" (p. 110, grifo meu), já que, em todas as formas nas quais se realizam as entrevistas, pode-se vislumbrar uma estrutura mínima que as unifica. Sendo assim, indagar se os eventos que compõem a constelação em questão (entrevista) equivalem a gêneros ou a subgêneros é uma questão da qual não se pode fugir. Caso equivalham a gênero é porque o autor enxerga alguma biunivocidade nessa relação. Se esses eventos que formam a constelação de entrevistas forem, como ele afirma, subgêneros, então estaremos diante de uma outra noção de subgênero, cuja ancoragem seria uma estrutura mínima, e não um subpropósito comunicativo, como propõe Bhatia $(1993 ; 1997 ; 1999)^{8}$.

Conforme defendem Marcuschi (2000) e Hoffnagel (2002), a entrevista é um gênero que também apresenta uma tendência constelar. Para o primeiro,

a entrevista é uma forma altamente institucionalizada, mas diversamente padronizada em virtude de suas funções. $O$ agrupamento representado pela expressão entrevista não reflete um tipo, mas uma constelação de eventos dos quais podemos chegar aos gêneros textuais (MARCUSCHI 2000, p. 111, grifos do autor).

Na mesma esteira, Hoffnagel (2002, p. 180) defende que a entrevista "é uma constelação de eventos possíveis que se realizam como gêneros (ou subgêneros) diversos" (grifo meu). Os dois autores aceitam que há uma variedade de funções, embora a estrutura da entrevista se conserve em suas variações. O que salta aos olhos é que a entrevista é um gênero discursivo que aceita variações, mesmo que o modelo

\footnotetext{
${ }^{8}$ Ora, os usos da expressão subgêneros por Marcuschi (2000) e por Bhatia (1997) torna fácil a constatação de que estamos diante de duas orientações teóricas bastante distintas e, por vezes, nebulosas. O elemento organizador da constelação, para Marcuschi, definitivamente, não é o mesmo eleito por Bhatia. Enquanto este sustenta que o propósito comunicativo comum aos gêneros é o critério unificador da constelação, o notável linguista brasileiro credita a uma possível estrutura mínima a função de atravessar e reunir os eventos que, no caso da entrevista, também poderiam ser chamados ao mesmo tempo de gêneros e de subgêneros.
}

ARAÚJO - Um percurso teórico-metodológico... 
canônico, representado pelo par dialógico pergunta-resposta (P-R), seja um aspecto permanente. Este, como mostra Fávero (2001, p. 96), "se configura como elemento imprescindível na organização do texto da entrevista", mas não nas muitas funções sociais que ela cumpre.

É preciso assinalar ainda que, para Marcuschi (2000), a expressão evento pode associar-se às noções de gênero, de subgênero e de suporte sociocognitivo (este, quando se refere à aula). Não deixando de considerar o fato de que não tenha sido seu propósito discutir e definir a categoria constelação de gêneros no trabalho que estou a resenhar aqui, devo dizer que, além de ser um trabalho inacabado, estamos diante de construções humanas que tentam, por meio de categorias, propor maneiras de olhar para o objeto.

Conforme evidenciarei mais adiante, embora haja discrepâncias entre uma e outra proposta de se conceber uma constelação de gêneros, é possível, ainda, estabelecer um ponto consensual entre Marcuschi e Bakhtin ([1929] 2002). É inegável que as tendências à imbricação, às variações, às transmutações constituem elementos que tornam complexas as atividades de investigação de alguns gêneros que tendem a se organizar em uma constelação, pois suscitam uma gama de categorias de análise que reflete esse universo instigante de estudo e pesquisa. De certo modo, essa realidade, ao mesmo tempo em que põe o analista em um terreno movediço, torna-o responsável pela definição de critérios, no mínimo "testáveis", que permitam o seu fazer científico. As tendências dos gêneros às variações e às transmutações, salientadas por Marcuschi (2000), fazem eco ao que Bakhtin ([1929] 2000), ainda nas primeiras décadas do século XX, escrevia sobre o fenômeno do agrupamento de gêneros.

\section{BAHKTIN E OS GÊNEROS DO SÉRIO-CÔMICO}

Para defender a tese de que Dostoiévski inaugura uma nova variante do romance (romance polifônico), Bakhtin ([1929] 2002) faz um levantamento exaustivo da história desse gênero, realizando uma verdadeira análise diacrônica. Ao investigar a evolução do romance, o autor procura reunir elementos que sejam comuns às variedades do gênero. Percorrendo esse viés metodológico, reserva atenção especial às transmutações e às hibridizações pelas quais passa o romance durante 
sua evolução. Como ele observa, a mistura de estilos e de gêneros não é uma novidade absoluta, posto que tal fenômeno remonta à Antiguidade Clássica. Exatamente por essa razão é que Bakhtin se dispõe a folhear "algumas páginas antigas da história dos gêneros [motivado pela suposição de que] essa digressão histórica ajudará a entender [...] as peculiaridades" do romance (p. 106) em seu estágio atual. Bakhtin segue esse caminho porque defende que um gênero

sempre conserva os elementos imorredouros da archaica. É verdade que nele essa archaica só se conserva graças à sua permanente renovação, vale dizer, graças à atualização. $\mathrm{O}$ gênero sempre é e não é o mesmo, sempre é novo e velho ao mesmo tempo. [...] Por isso, não é morta a archaica que se conserva no gênero; ela é eternamente viva, ou seja, é uma archaica com capacidade de renovar-se. O gênero vive do presente, mas recorda o seu passado, o seu começo [...]. É precisamente por isto que tem a capacidade de assegurar a unidade e a continuidade desse desenvolvimento ([1929] 2002, p. 106, grifos do autor).

Paulo Bezerra, tradutor da obra Problemas da poética de Dostoiévski, em nota de pé de página, informa que o termo archaica, no sentido etimológico, vem do grego e quer dizer "traços característicos e distintos dos tempos antigos" (p. 106). Sabiamente, Bakhtin ([1929] 2002) estende esse sentido para explicar o fenômeno da variação dos gêneros do discurso. Para o autor russo, todo gênero guarda consigo traços de seu passado.

Isso significa que é possível realizar um estudo da história dos gêneros, como fizeram, por exemplo, Orlikowski e Yates (1994), ao resgatar a história da carta; Bazerman (1988; 2005), ao estudar a evolução do artigo científico de 1665 a 1800 ou o status da carta enquanto gênero basilar de outros; Simeon Yates (2000), ao trazer revelações históricas bastante curiosas acerca da carta e do memorando até chegar ao e-mail; Biasi-Rodrigues (2008; 2010), ao mostrar traços de permanência e mudanças ao estudar a evolução do anúncio na publicidade cearense, e Zavam (2009), que analisou a evolução do editorial no jornalismo cearense. Orientados por essa base epistemológica bakhtiniana, o que guiou esses estudiosos foi a certeza de que todo gênero conserva seus 
elementos imorredouros ${ }^{9}$ e acessá-los foi importante para remontar a sua história.

O que me interessa nos autores supracitados é o fato de todos concordarem com a existência de uma relação genética que irmana o gênero com suas variedades. Ou seja, todo gênero possui uma archaica ou uma força que lhe é peculiar capaz de fazê-lo gerar outros gêneros que lhe sejam cognatos. Essa reflexão é muito necessária ao conceito de constelação a que quero chegar, porque acredito que, uma vez gerados, esses "novos" gêneros passam a servir a outros propósitos comunicativos sem perder, no entanto, a relação genética uns com os outros. Assim, como será mostrado mais adiante, tanto o critério diacrônico quanto o sincrônico são relevantes para construir um possível percurso que ajude na caracterização de uma constelação de gêneros. Enquanto o primeiro permite o estudo das transmutações dos gêneros dentro da constelação, o segundo é útil para a análise dos propósitos comunicativos que os tornam diferentes.

Concomitantemente à existência da archaica, os pesquisadores se deparam com outra característica forte dos gêneros do discurso: ser novo e velho ao mesmo tempo. Trata-se da já mencionada condição paradoxal da existência do gênero, que sem dúvida é uma vexata quaestio para os que a eles se dedicam. Basta consultar a literatura especializada para vermos o quanto essa condição contraditória da existência do gênero atrai a atenção dos analistas, que convivem com esse paradoxo do qual fala Bakhtin, ou seja, um gênero sempre é velho e novo ao mesmo tempo. Acerca desse paradoxo, Marcuschi (2002) muito bem nos lembra de que são as alterações ocorridas nos domínios discursivos que permitem que se usem "velhas bases" para novos propósitos comunicativos dos gêneros. Essa consideração marcuschiana deixa uma fresta preciosa para que se perceba a relevância dos aspectos diacrônicos e sincrônicos para empreender um estudo sobre os gêneros, sobretudo aqueles que se agruparam em torno de características específicas.

\footnotetext{
${ }^{9}$ É importante dizer que a opção pelo estudo da evolução de um gênero feita por esses autores foi assumida por mim em outros trabalhos já citados aqui. Mesmo que os chats sejam gêneros muito jovens, é importante considerar o critério diacrônico no estudo de sua organização constelar, já que os dados que analisei reforçam a tese de que todos os chats vieram de outros gêneros (ARAÚJO, 2006).
} 
Consciente dessa realidade, Bakhtin assume a empreitada de justificar que Dostoiévski criou um novo tipo de romance e, por isso, ele se lança às páginas da Antiguidade Clássica e do Helenismo para investigar a história do que ele designaria romance polifônico. $\mathrm{O}$ meu interesse nessa investigação do autor russo reside em seus primeiros achados: trata-se de um conjunto muito especial de gêneros que se desenvolveram nas épocas citadas. Foi a análise desse conjunto de gêneros que atraiu a minha atenção porque, ainda que se mostrassem distintos entre si, Bakhtin considerou que tais gêneros eram cognatos. A esse grupo de gêneros, ele denominou campo do sério-cômico ${ }^{10}$. A própria dinâmica de seu estudo lhe impôs a seguinte questão: "em que consistem as particularidades características dos gêneros do sério-cômico"? (BAKHTIN[1929] 2002, p. 107), o que mostra claramente que Bakhtin seguiu o critério funcional. A fim de tornar mais visual esse conjunto de gêneros para o leitor, elaborei a figura 111, a seguir, a partir das palavras de Bakhtin.

Todos os gêneros dessa constelação pertencem à esfera literária e, por isso, a carnavalização, que melhor caracteriza essa esfera, é uma espécie de "marca mãe" que os irmana, sendo, portanto, um dos principais eixos organizadores desse agrupamento constelar. Como esclarece Bakhtin, essa característica mãe se triparte para atender à heterogeneidade do campo literário. Assim, o aspecto carnavalesco, que está no topo da figura, desencadeia um movimento cíclico anti-horário que parece determinar as características desses gêneros: um novo tratamento da realidade, o qual está baseado na fantasia livre para criar e realizar combinação e transmutação de outros gêneros e de outros estilos. Pelo que se pode inferir da leitura que fazemos de Bakhtin, todas essas características operam em conjunto, de maneira que as separações que farei no parágrafo subsequente devem servir unicamente para que se vislumbrem suas tênues e entrelaçadas fronteiras.

\footnotetext{
${ }^{10}$ Neste caso, a metodologia bakhtiniana é de cunho diacrônico porque o autor parte, como veremos, dos gêneros do sério-cômico. Dele, extrairá os dois gêneros mais carnavalizados: o Diálogo Socrático e a Sátira Menipeia. O afunilamento do estudo diacrônico permitirá a conclusão de que a sátira menipeia foi o gênero mais carnavalizado do grupo acima e, portanto, é dela que procede o romance polifônico criado por Dostoiévski.

${ }^{11}$ Agradeço ao professor Rafael Costa (UFC/FIC) por melhorar consideravelmente a estética das figuras 1 e 2 apresentadas neste ensaio.
}

ARAÚJO - Um percurso teórico-metodológico... 
Figura 1 - Constelação dos gêneros do sério-cômico:

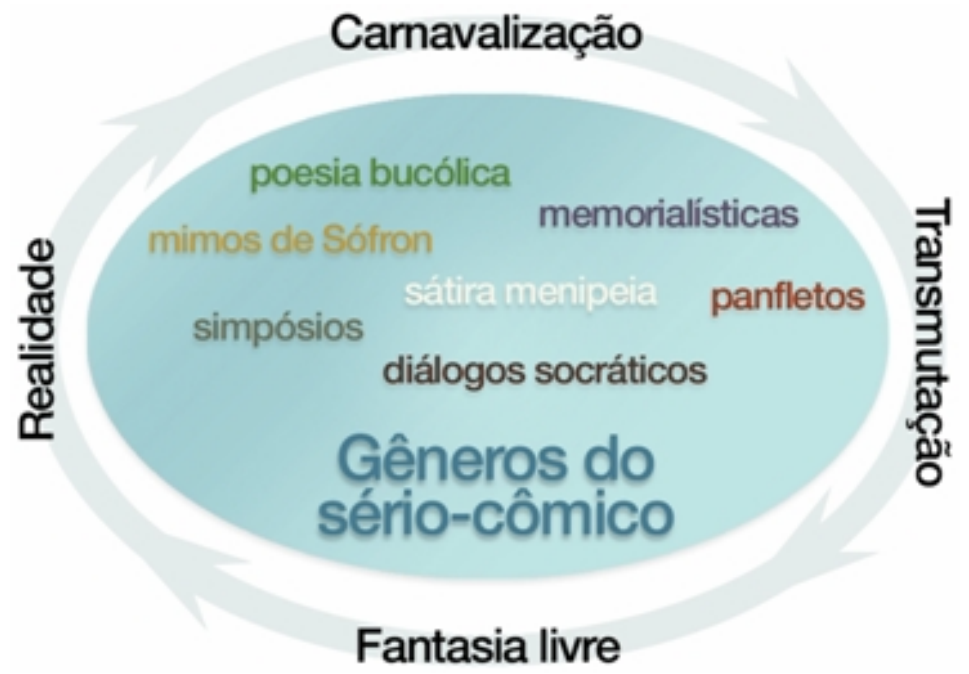

Fonte: Elaboração própria.

Em relação ao novo modo de tratar a realidade, Bakhtin ([1929] 2002, p. 108) mostra que os gêneros do sério-cômico reinterpretam os mitos, os quais são deliberadamente atualizados. Para o autor, "pela primeira vez, na literatura antiga, o objeto da representação séria (e simultaneamente cômica) é dado com os contemporâneos vivos, e não no passado absoluto dos mitos e lendas". Imediatamente correlata à primeira, a segunda característica é destacada porque ela realça a natureza da reinterpretação que esses gêneros fazem das lendas e mitos. Como informa o autor, o modo como os gêneros do campo sério-cômico tratam o mito chega a ser "cínico- desmascarador"12, o que representa, para a época, "uma verdadeira reviravolta na história da imagem literária”. A terceira e última característica é a mais cara à carnavalização, porque aí é possível vislumbrar mais claramente um dos fenômenos de

\footnotetext{
${ }^{12} \mathrm{O}$ fato de esses gêneros subverterem os cânones das lendas e mitos, remete-nos, de certo modo, ao que Maingueneau (1997, p. 104) denomina subversão. Para o linguista francês, no "mecanismo da subversão [...] as condições genéricas são respeitadas, mas o texto as desqualifica em sua própria enunciação".
} 
meu interesse para definir o que seja uma constelação de gêneros: a transmutação. De acordo com Bakhtin ([1929] 2002, p. 108), os gêneros do campo do sério-cômico transmutam e, por vezes, subvertem outros gêneros, como cartas, manuscritos encontrados, diálogos relatados, paródias dos gêneros elevados, citações recriadas em paródias, etc. Em alguns deles, observa-se a fusão do discurso da prosa e do verso, inserem-se dialetos e jargões vivos.

Por conta disso, a conclusão do estudioso é a de que

esses gêneros estão conjugados por uma profunda relação com o folclore carnavalesco. Variando de grau, todos eles estão impregnados de uma cosmovisão carnavalesca específica e alguns deles são variantes literárias diretas dos gêneros folclóricocarnavalescos orais. A cosmovisão carnavalesca, que penetra totalmente esses gêneros, determina-lhes as particularidades fundamentais... ([1929] 2002, p. 108, grifos do autor).

Essa última asserção é reveladora de que, mesmo que o autor não tenha mencionado textualmente a categoria constelação de gêneros, tal noção parece estar subjacente às suas reflexões. Dessa última citação é possível depreender então o que caracterizaria uma constelação.

Em primeiro lugar, é condição sine qua non que os gêneros sejam conjugados entre si por algum traço maior da esfera que os ambienta, capaz de irmaná-los (no caso específico, é o folclore carnavalesco). Em segundo lugar, afigura-se importante destacar que o fato de os gêneros assumirem um caráter de "família" não significa que a constelação seja homogênea, pois, segundo a asserção bakhtiniana, os gêneros apresentam graus diferentes $\mathrm{da}(\mathrm{s})$ característica(s) que os congrega(m). Com essa citação, pode-se realçar ainda a importância que Bakhtin atribui à pré-existência dos gêneros. Esse realce é relevante porque me encoraja na sugestão hipotética segundo a qual os gêneros folclóricocarnavalescos orais foram transmutados pelos gêneros que formam o campo do sério-cômico.

Mas a análise da evolução do gênero romanesco não se esgota nos gêneros do sério-cômico, pois o estudo dessa constelação de gêneros consistiu, para Bakhtin ([1929] 2002), apenas no ponto de partida para 
alcançar as "variedades da linha carnavalesca" (p. 109), na qual se insere o romance polifônico de Dostoiévski, objeto de estudo do autor. Dos gêneros apresentados na figura 1, Bakhtin faz um exame mais minucioso do diálogo socrático e da sátira menipeia (doravante DS e SM, respectivamente). Essa escolha do autor se justifica porque tais gêneros são determinantes para a formação dos romances carnavalescos. Para tornar essa discussão mais clara, passo a apresentá-los à luz da análise de Bakhtin.

O DS foi um gênero de natureza histórica e memorialística, pois sua materialidade literária advém de "recordações das palestras reais proferidas por Sócrates” (p. 109). Assim como os demais gêneros que formam a constelação apresentada na figura 1, o DS é atravessado pela carnavalização, portanto não lhe cabe a rubrica de um gênero retórico. Bakhtin ([1929] 2002) elenca cinco características definidoras do DS.

A primeira delas é análoga ao método maiêutico de Sócrates ${ }^{13}$, o que corresponde ao próprio nome do gênero, cuja função tende ser a busca pela natureza da verdade. Essa característica justifica a segunda, que é a existência de dois procedimentos que funcionam como estratégias discursivas: a sincrese e a anácrise. Enquanto o primeiro procedimento consiste em propiciar o maior número possível de opiniões acerca de um objeto, o segundo funciona como uma estratégia de suscitar nos interlocutores a exteriorização dessas opiniões.

Quando isso ocorre, o gênero carnavalizado apresenta sua terceira característica: seus heróis. Os heróis do DS são, nas palavras de Bakhtin, ideólogos que buscam avidamente pela verdade. Para tanto, travam-se acirrados debates, o que conduz o gênero à quarta característica, ou seja, a necessidade de um enredo, já que sua organização textual é de natureza narrativa. Para finalizar, o DS opera ainda com a junção entre a ideia e o homem, os quais são, organicamente, combinados. $\mathrm{Na}$ opinião de

\footnotetext{
13“"O método da arte maiêutica - o método socrático - consiste em levar o interlocutor à descoberta da verdade mediante uma série de perguntas e mediante as perplexidades a que as respostas vão dando origem. Na maiêutica, acha-se implicada a ideia da reminiscência que se manifesta no reconhecimento da verdade, quando se apresenta à alma". (DICIONÁRIO DE FILOSOFIA, 2010).
} 
Bakhtin, todas essas características tornam o DS um gênero relevante na história do que futuramente será um romance polifônico.

Ainda que o DS tenha sido um gênero bastante influenciador na evolução do romance, ele teve vida breve. Sua decomposição, no entanto, não se deu em um momento único, mas foi processual. Esse processo de desintegração, como bem realça Bakhtin, foi muitíssimo produtivo, pois dele desenvolveram-se outros gêneros, como a SM, por exemplo. Ainda que a sátira menipeia tenha se desenvolvido a partir da decomposição do diálogo socrático, Bakhtin ([1929] 2002, p. 112) pondera que as SM's "não podem ser consideradas como produto genuíno da decomposição do discurso socrático, pois as raízes delas remontam diretamente ao folclore carnavalesco".

Não obstante a carnavalização do DS, a SM consegue ir mais além, pois se caracteriza como o gênero mais carnavalizado da constelação do campo do sério-cômico, além de ser o gênero com um maior grau de absorção, posto que de todos que formam a constelação apresentada na figura 1, a SM é a que mais transmuta outros gêneros para o seu interior. Para Bakhtin ([1929] 2002, p. 120), esse gênero tem "uma capacidade excepcional de absorver os pequenos gêneros cognatos e penetrar nos outros gêneros grandes"14. Esse caráter absortivo, portanto, singulariza a SM, além de torná-la um gênero de um alto grau de complexidade dentro da referida constelação. Por essa razão, Bakhtin enxerga nesse gênero a base sobre a qual se ergue a variedade de romance que seria denominada por ele romance polifônico.

De posse dessa conclusão, o autor considera que o romance de Dostoiévski é o estágio contemporâneo da SM, já que, segundo sua análise, é possível capturar muitos índices deste gênero naquele. Entre esses índices, devido à carnavalização, destacam-se, principalmente, a transmutação de tantos outros gêneros, a combinação e a subversão de estilos e, sobretudo, a polifonia.

\footnotetext{
${ }^{14}$ Assim, em sua órbita, gravitam gêneros outros, como a diatribe, o solilóquio, o simpósio e o logistoricus. Respectivamente, gênero retórico que se constrói em função de um diálogo com um interlocutor ausente; gênero que trava um diálogo consigo mesmo; gênero dos diálogos dos festins; gênero resultado da fusão do DS com as histórias fantásticas.
}

ARAÚJO - Um percurso teórico-metodológico... 


\section{CONSTELANDO OS ARGUMENTOS E PROPONDO TRILHAS}

Como pode ser percebido, no contexto deste ensaio, Marcuschi (2000, p. 111) representa um importante avanço na discussão sobre a categoria de constelação de gêneros no sentido de perceber que os gêneros se constelam por um critério de família, já que para ele, por exemplo, “o agrupamento representado pela expressão entrevista não reflete um tipo, mas uma constelação de eventos dos quais podemos chegar aos gêneros". Essa perspectiva parece estar em consonância com o que postula Bakhtin, pois, assim como Marcuschi, o autor russo compreende que um grupo de gêneros se organiza por características que lhe sejam familiarmente comuns, o que não significa serem os gêneros iguais.

Em seu estudo, Bakhtin confere uma singular importância ao critério diacrônico porque entende que o estudo das transmutações pode revelar similaridades e diferenças entre os gêneros constelados. Pela leitura de seu trabalho, fica claro que os gêneros devem estar conjugados por um traço maior que represente uma característica saliente da esfera na qual eles se ambientam. Como a esfera estudada pelo autor foi a literária, ele percebeu que a carnavalização seria a marca mais saliente desse campo. Tal característica atinge, em diferentes graus, todos os gêneros do campo do sério-cômico.

Com base nessas considerações, concentro esforço para encetar a construção de um pretenso percurso teórico-metodológico que permita fundamentar a maneira como reflito sobre a categoria constelação de gêneros. Para que essa proposta seja mais bem compreendida, preciso começar dizendo que, no contexto deste ensaio, entendo que um estudo que queira empreender a caracterização de uma constelação de gêneros deve se estruturar a partir de três eixos temáticos fundamentais, quais sejam: 
a) a(s) esfera(s) de comunicação em que tais gêneros se $\operatorname{ambientam}^{15}$;

b) as marcas de sua formação genérica;

c) as suas funções sociais dentro da constelação.

Começar pela investigação da esfera de comunicação é importante porque permite ao pesquisador ter acesso à ambiência onde ocorrem as práticas discursivas que engendram a constelação de gêneros. Mas, antes disso, é preciso se perguntar: o que é uma esfera de comunicação? Este conceito, que também procede de Bakhtin ([1953] 2000), aparece em seu famoso ensaio sobre Os gêneros do discurso. O que esse autor chama de esferas de comunicação equivale ao que Marcuschi (2002, p. 23) denomina domínio discursivo, expressão usada

para designar uma esfera ou instância de produção discursiva ou de atividade humana. Esses domínios não são textos nem discursos, mas propiciam o surgimento de discursos bastante específicos". (itálico do autor, negritos meus).

Pela citação, infere-se que as categorias esfera, atividade, produção e discurso inscrevem Marcuschi na proposta bakhtiniana de gêneros. Não obstante a variação do uso dos termos correlatos que também farei aqui, o leitor perceberá minha preferência pela nomenclatura bakhtiniana. Isso se justifica porque na expressão esfera de comunicaşão bumana há a junção de três importantes noções que se coadunam para gerar a ideia de um espaço onde se realizam atos ou atividades humanas ${ }^{16}$ através da linguagem.

Em primeiro lugar, a noção cíclica da vida que se renova constantemente subjaz ao signo esfera. Esta se dilata cada vez mais, na medida em que se espraiam as inesgotáveis possibilidades de interação

\footnotetext{
${ }^{15}$ Reconheço que as constelações de gêneros são muitas e que, por isso, os gêneros que as compõem podem estar em esferas distintas. A carta, por exemplo, é uma constelação cujos gêneros se ambientam em esferas diferentes (cf. MAIOR; BEZERRA, 2000). Assim, não descarto a possibilidade de encontrar constelações de gêneros que se ambientam em esferas diferentes e outras cujos gêneros se ambientam em uma única esfera.

${ }^{16}$ Para um maior aprofundamento sobre as categorias de ato e atividade em Bakhtin, sugiro a leitura do elucidativo ensaio de Sobral (2005).
}

ARAÚJO - Um percurso teórico-metodológico... 
humana. Em seguida, a noção de ação em comum ou de (inter)ação parece vir à tona através da palavra comunicaçã $0^{17}$. Finalmente, o caráter de humanidade, flagrado pela expressão bumana, realça em que de fato Bakhtin acredita: a língua é um lugar onde as relações entre os humanos se prosificam, no sentido discutido por Machado (2005). Isso encoraja a afirmação segundo a qual, para Bakhtin, é impossível pensar em gêneros do discurso sem associar tal conceito ao de esferas de comunicação.

De minha parte, entendo que esfera de comunicação é uma instância discursiva que propicia o desenvolvimento de práticas sociais, as quais se materializam nos gêneros que lhes são peculiares, de maneira que estes sempre trazem em sua configuração marcas daquela. Dessa maneira, compreendo ainda que o conceito em tela se mostra bastante produtivo para a explicação do surgimento de gêneros do discurso cada vez mais complexos.

Seguindo a orientação de Bakhtin, deve-se ter em mente que, quando as necessidades enunciativas dos indivíduos se complexificam, é sinal de que o espaço de comunicação no qual estão inseridos os sujeitos também sofre alterações. Inevitavelmente, os gêneros se complexificam, reinterpretando outros em função dos novos propósitos comunicativos e das novas relações sociais que emergem dessas alterações. Consoante tal perspectiva, mediante a evolução das esferas, novos gêneros surgem para [re]organizar as práticas discursivas ocorridas nesses espaços, o que permitiu o consenso entre os estudiosos de que, para Bakhtin ([1953] 2000), os gêneros não são estáticos, mas se [re]ajustam às necessidades comunicativas do homem.

Tendo explicado o que entendo por esfera de comunicação, é necessário dizer que assumi-la como fase primária do estudo de uma constelação de gêneros traz implicações de caráter teórico e metodológico importantes para a atividade de pesquisa. Do ponto de vista teórico, Bakhtin ([1953] 2000) defende que os gêneros refletem as características e as finalidades de suas esferas, portanto, como adverte Brait (2001), considerá-las é importante para não cairmos em uma ideia

${ }^{17}$ Não no sentido defendido pela Teoria da Comunicação. 
mecanicista de gênero. Além disso, um estudo de um grupo de gêneros que compartilham características comuns não começaria bem se o pesquisador não compreendesse que os gêneros são ferramentas semiotizadas pelas necessidades humanas que surgem dentro de seus territórios sociopragmáticos.

No tocante ao aspecto metodológico, pode-se observar que é relevante considerar a esfera de comunicação em estudos sobre a constelação de gêneros porque o analista assumiria uma postura de caráter etnográfico, a fim de compreender os usos dos gêneros à luz de seus produtores/consumidores. Como podemos ver, este primeiro passo do percurso teórico-metodológico investe a pesquisa de um caráter mais qualitativo, pois, como também fez Swales (2004) para estudar as constelações de gêneros acadêmicos, é importante que o estudo se paute por uma observação participante do pesquisador. Essa postura é importante porque por ela o pesquisador poderá capturar a característica mais saliente da esfera discursiva para observar em que medida tal característica influencia os gêneros organizados na constelação-alvo.

Uma vez imerso nos ambientes sociodiscursivos dos gêneros, o pesquisador tem condições de dar o segundo passo de seu percurso, que é o de buscar nas esferas discursivas indícios sobre o processo formativo dos gêneros que compõem a suposta constelação. Esse critério diacrônico é indispensável para o presente constructo, pois do contrário fica difícil conseguir detectar as marcas do processo formativo dos gêneros. Considerar a evolução dos gêneros que se constelaram é muito importante, pois ela pode revelar aspectos que ajudem ao analista na construção do entendimento acerca de determinadas propriedades genéricas que possam ser comuns ou não a toda a constelação. Desse modo, minha suposição é a de que, rastreando as características do processo de formação genérica, o estudioso poderá verificar em que medida esse processo permite a caracterização da constelação (ARAÚJO, 2004).

Finalmente, o estudo deverá focalizar as funções sociais dos gêneros, terceiro passo do percurso teórico-metodológico. Ao entrar nessa fase da pesquisa, o analista deverá orientar-se pelo estágio sincrônico dos gêneros constelados. Ou seja, é preciso verificar como as 
marcas da evolução foram reinterpretadas em função dos propósitos sociais que os gêneros, em seu estágio atual, atendem. Penso que essa fase permitirá a verificação da heterogeneidade funcional da constelação, pois, de acordo com Swales (2004, p. 68), se "um gênero é um agregado de eventos comunicativos que preenchem uma função social comum" (grifos meus), imagine-se o que se pode encontrar em se tratando de uma constelação deles. O estudo deste último aspecto é, ainda, importante porque, por ele, dados podem ser construídos para auxiliarem na compreensão de que "o fato de serem membros de uma constelação [...] não torna homogêneos [...] os gêneros" (ARAÚJO, 2004, p. 1282), pois a teia de funções sociais que atravessa a constelação os diferencia entre si (ARAÚJO, 2006).

A figura 2 sintetiza as explicações precedentes.

Figura 2 - Percurso para a investigação de uma constelação de gêneros:

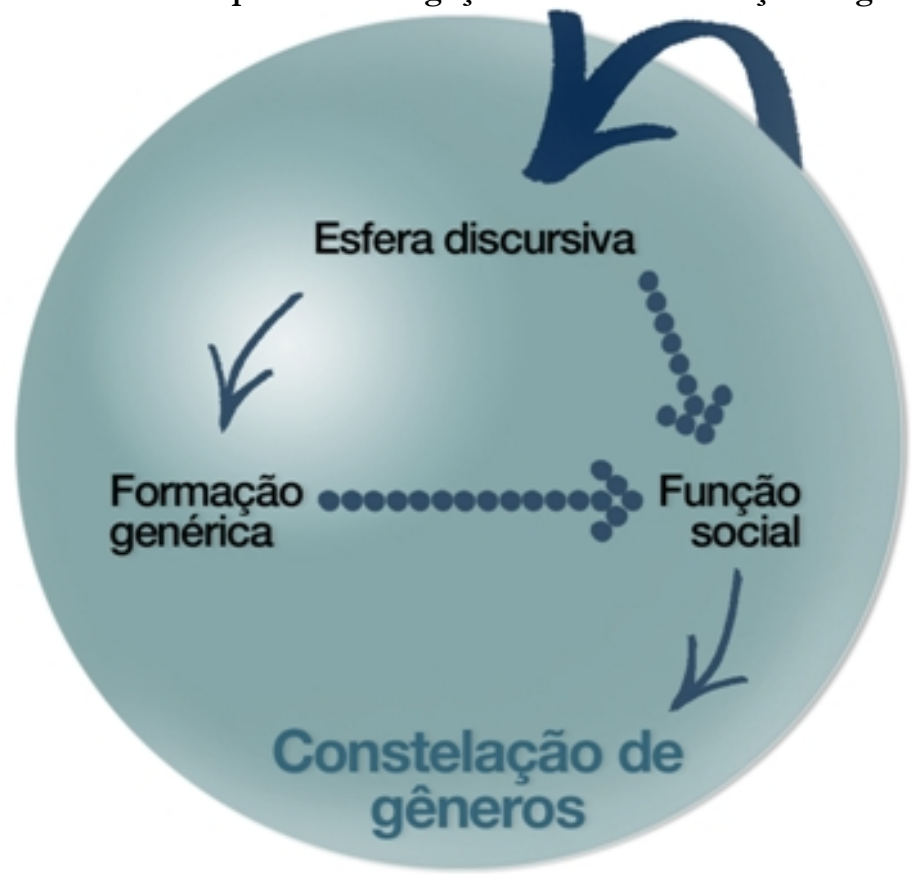

Fonte: Elaboração própria. 
Nenhuma esfera é fechada em si mesma, pois, ao mesmo tempo em que pode ter seus gêneros absorvidos, pode também transmutar não apenas gêneros, mas também outras esferas (ARAÚJO, 2010). A base epistemológica para essa explicação procede do materialismo dialético, no qual Bakhtin ([1929] 1981) se inspirou para construir uma concepção de linguagem sociocultural. Evidentemente, tal concepção destoa daquela fundada por Saussure ([1916] 1995), o qual, segundo o autor russo, "ignora [...] o fato de que, além das formas da língua, há também as formas de combinação dessas formas, ou seja, os gêneros do discurso" (BAKHTIN [1953] 2000, p. 304).

É com essa base teórica que a figura retoma, além da noção de esfera, os passos que podem permitir que o analista perceba as semelhanças e as diferenças entre os gêneros de uma constelação qualquer. A seta que entra na elipse indica não só a inserção do pesquisador dentro da esfera, mas também serve para sinalizar o começo de uma formação genérica que, por estar sendo transmutada pela esfera, começará um dinâmico processo de constituição. Por isso, entrar no domínio discursivo para compreender as especificidades da constelação deve ser o primeiro passo da investigação, pois por ele é possível chegar às semelhanças entre os gêneros graças ao exame minucioso das características de sua ambiência sociodiscursiva.

As setas seguintes indicam o interesse em estudar o processo formativo dos gêneros. Da seta localizada na parte superior esquerda da figura sai outra seta pontilhada indicando que a formação genérica deixa rastros dentro da esfera e, por isso, o pesquisador precisa estar atento a essas marcas, pois, ao rastreá-las, poderá estudar como elas foram reinterpretadas dentro da constelação e como os autênticos produtores/consumidores desses gêneros as reconhecem. Provavelmente, essas marcas levarão o investigador a descobrir como elas foram ressignificadas pelos novos gêneros, o que suscita a sugestão de que esse percurso o leve a conhecer melhor os papéis sociais dos gêneros que, em função das necessidades humanas que geraram esse processo, possivelmente atendem a propósitos comunicativos distintos. Assim, enquanto as características das esferas discursivas e as marcas do 
processo formativo servem para uma possível aproximação entre os gêneros, o estudo de suas funções sociais pode ajudar na construção da compreensão da heterogeneidade social da constelação.

A figura mostra ainda uma segunda seta pontilhada que procede do termo esfera discursiva. Ela sugere que a própria esfera já pode servir como uma primeira pista para se chegar à funcionalidade dos gêneros. Não obstante isso, considero que partir da esfera para conhecer a função social dos gêneros sem antes estudar o processo formativo deles pode ser imprudente, pois estou convencido de que é pelo rastreamento dos indícios da formação genérica que se poderá obter uma aproximação da funcionalidade social dos gêneros.

Contudo, dizer simplesmente que o analista deve considerar os três eixos temáticos acima discutidos não torna exequível a análise da constelação, pois falta precisar as categorias de análise que poderiam tornar operante o estudo. Quanto a isso, poderia dizer que não há como generalizar as categorias de análise da mesma forma que fiz com os eixos temáticos, pois, assim como os gêneros, as constelações são diversas e seu estudo exigirá sempre adaptações. Assim, as categorias devem ser extraídas dos eixos temáticos, já que eles parecem poder ser generalizáveis aos possíveis tipos de constelação. Porém, essa extração não deve acontecer de qualquer modo, é preciso que o analista considere muitíssimo as especificidades da constelação que ele pretende estudar, atentando, sobretudo, para as esferas de comunicação que ambientam os gêneros que se constelaram. Precisar categorias de análise das constelações é adentrar a realidade empírica dos dados. Isso é, portanto, um tema para um próximo ensaio.

\section{REFERÊNCIAS}

ARAÚJO, J. C. A organização constelar do gênero chat. In: JORNADA NACIONAL DE ESTUDOS LINGUÍSTICOS. 20., 2004. Anais ... João Pessoa, 2004, p. 1279-1292.

Os chats: uma constelação de gêneros na internet. 2006. 341 f. Tese (Doutorado em Linguística) - Programa de Pós-graduação em Linguística, Universidade Federal do Ceará, Fortaleza, 2006. 
. Transmutação de gêneros na web: a emergência do chat. In:

MARCUSCHI, L. A.; XAVIER, A. C. (Org.). Hipertexto e gêneros digitais: novas formas de construção do sentido. 3 ed. São Paulo: Cortez, 2010, p. 109134.

BAKHTIN. M. Marxismo e filosofia da linguagem. São Paulo: Hucitec, 1981.

Estética da criação verbal. São Paulo: Martins Fontes, 2000.

. Problemas da poética de Dostoiévski. 3 ed. Rio de Janeiro: Forense Universitária, 2002.

BAZERMAN, C. Shaping written knowledge: The genre and activity of the experimental article in science. Madison: University of Wisconsin Press, 1988.

Gêneros textuais, tipificação e interação. Trad. e organização de Ângela P. Dionísio e Judith C. Hoffnagel. São Paulo: Cortez, 2005.

BEZERRA, B. G. Gêneros introdutórios em livros acadêmicos. 2006. 256 f. Tese (Doutorado em Linguística) - Programa de Pós-graduação em Letras, Universidade Federal de Pernambuco, Recife, 2006.

. Agrupamentos de gêneros: discutindo terminologias e conceitos. In: CONGRESSO INTERNACIONAL DA ABRALIN. 7., 2011. Anais ... Curitiba, 2011, p. 602-610.

BHATIA, V. K. Analysing genre: language use in professional settings. New York: Longman, 1993.

. Genre analysis today. Revue Belge de Philologie et d'Histoire, v. 75, n. 3, p. 629-652, 1997.

. Integrating products, processes, purposes and participants in professional writing. In. CANDLIN, C. N. ; HYLAND, K. (Eds.).Writing: texts, processes and practices. New York: Longman, 1999. p. 21-39.

. Applied genre analysis: analytical advances and pedagogical procedures. In: JOHNS, A. M. (Ed.). Genre in the classroom: multiple perspectives. Mahwah, Nj: Lea, 2001. p. 279-283.

.Worlds of written discourse: a genre-based view. London: Continuum, 2004.

BIASI-RODRIGUES, B. Estratégias de condução de informações em resumos de dissertações. 1998. 205 f. Tese (Doutorado em Linguística). 
Programa de Pós-graduação em Letras/Linguística, Universidade Federal de Santa Catarina, Florianópolis, 1998.

. O gênero anúncio: tradição e atualidade. In: XV Congreso

Internacional de la Asociación de Lingüística y Filología de América

Latina. Montevidéu, 2008, v. 1. p. 1-10.

- A trajetória do gênero anúncio em jornais cearenses dos séculos XIX e

XX. In: ARAÚJO, J. C, BIASI-RODRIGUES, B.; DIEB, M. (Orgs.).

Seminários linguísticos: discurso, análise linguística, ensino e pesquisa.

Mossoró: Edições UERN, 2010. p. 17-33.

BOURDIEU, P. O poder simbólico. Tradução de Fernando Tomaz. 11.ed. Rio de Janeiro: Bertrand Brasil, 2007.

BRAIT, B. O discurso sob o olhar de Bakhtin. In. GREGOLIN, M. DO R.; BARONAS, R. (Orgs.) Análise do discurso: as materialidades do sentido. São Paulo: Claraluz, 2001.

CHEPTULIN, A. A dialética materialista: categorias e leis da dialética. São Paulo: Alfa-Omega, 1982.

DICIONÁRIO de Filosofia. 3 (K-P), Volume 3. Disponível em:

<http://www.books.google.com.br/books?isbn=8515020068> Acesso em: set. 2010.

FÁVERO, L. L. A entrevista na fala e na escrita. In. PRETI, D. (Org.). Fala e escrita em questão. 2 ed. São Paulo: Humanitas/FFLCH/USP, 2001. p. 79-97.

HOFFNAGEL, J. C. Entrevista: uma conversa controlada. In: DIONÍSISO, A.; MACHADO, A. R.; BEZERRA, M. A. (Org.) Gêneros textuais \& ensino. Rio de Janeiro: Lucerna, 2002. p. 180-193.

LOPES, A. K. C. Uma colônia de gêneros anúncios. 2008. 181 f. Dissertação (Mestrado em Linguística) - Programa de Pós-graduação em Linguística, Universidade Federal do Ceará, Fortaleza, 2008.

MACHADO, I. Os gêneros do discurso. In: BRAIT, B. (Org.). Bakhtin: conceitos-chave. São Paulo: Contexto, 2005. p. 151-166.

MAINGUENEAU, D. Novas tendências em análise do discurso.

Campinas: Pontes, 1997.

MAIOR, A. C. S.; BEZERRA, M. A. O gênero 'carta' e suas variedades. In: JORNADA NACIONAL DE ESTUDOS LINGUÍSTICOS. GRUPO DE ESTUDOS LINGUÍSTICOS DO NORDESTE (GELNE)/Universidade 
Federal do Ceará (UFC) e Universidade Federal da Bahia (UFBA). 18., 2000. Anais... Salvador:, 2000, p. 740-743.

MARCUSCHI, L. A. Gêneros textuais: o que são e como se constituem. Recife: Universidade Federal de Pernambuco. Texto inédito, 2000. Cortez, 2001.

Da fala para a escrita: atividades de retextualização. 3 ed. São Paulo: . Gêneros textuais: definição e funcionalidade. In: DIONÍSIO, A., MACHADO, A. R.; BEZERRA, M. A. (Orgs.). Gêneros textuais e ensino. Rio de Janeiro: Lucerna, 2002. p. 19-36.

. Gêneros textuais emergentes no contexto da tecnologia digital. In: MARCUSCHI, L. A..; XAVIER, A. C. (Orgs.). Hipertexto e gêneros digitais: novas formas de construção de sentido. Rio de Janeiro: Lucerna, 2004. p. 13-67.

Gêneros textuais: configuração, dinamicidade e circulação. In: KARWOSKI, A. M., GAYDECZKA, B. \& BRITO, K. S. (Orgs.). Gêneros textuais: reflexões e ensino. União da Vitória: Kaygangue, 2005. p. 17-33.

MARX, K. Contribuição à crítica da economia política. São Paulo: Martins Fontes, 1983.

ORLIKOWSKI, W. J.; YATES, J. Genre repertoire: norms and forms for work and interaction. Disponível em: <http://ccs.mit.edu/papers/CCSWP166.html>, 1994. Acesso em: 15 nov. 2003.

SAUSSURE, F. Curso de linguística geral. 20 ed. São Paulo: Cultrix, 1995.

SOBRAL, A. Ato/atividade e evento. In: BRAIT, B. (Org.). Bakhtin: conceitos- -chave. São Paulo: Contexto, 2005, p. 11-36.

SWALES, J. M. Research genres: explorations and applications. New York: Cambridge University Press, 2004.

YATES, S. J. Computer-Mediated Communication. The Future of the Letter? In: BARTON. D.; HALL, N. (Eds.) Letter writing as a social practice. Amsterdam/Philadelphia: John Benjamins, 2000, p. 233-251.

ZAVAM, A. Por uma abordagem diacrônica dos gêneros do discurso à luz da concepção de tradição discursiva: um estudo com editoriais de jornal. 2009. 420 f. Tese (Doutorado em Linguística) - Programa de Pós-graduação em Linguística, Universidade Federal do Ceará, Fortaleza, 2009. 
Recebido em 08/08/11. Aprovado em 11/04/12.

Title: A theoretical-methodological journey for the study of genre constellations

Author: Júlio César Araújo

Abstract: In this essay, I propose a theoretical-methodological journey that permits to substantiate a possible reflection about the phenomenon of discursive genre grouping. Therefore, I undertake an analysis of the arguments of Marcuschi (2000) and Bakbtin ([1929] 2002) about the groups of genres. Although there are discrepancies between both proposals for conceiving a constellation of genres, it is possible to establish a consensual point between these researchers in that both highlight the tendencies of the genres to variations and transmutations. The effects of this analysis permit the conclusion that a study which will undertake the characterization of a genre constellation must be structured from three fundamental thematic axles: the sphere(s) of communication in which such genres adapt themselves; the tracks left during its process of formation and the communicative purposes attended by each genre inside the constellation.

Keywords: Genre constellation. Sphere of communication. Transmutation. Communicative purpose.

Título: Un recorrido teórico-metodológico para el estudio de constelaciones de géneros Autor: Júlio César Araújo

Resumen: En este ensayo, propongo un recorrido teórico-metodológico que permita fundamentar una posible reflexión sobre el fenómeno de agrupamientos de géneros discursivos. Para tanto, emprendo un análisis de los argumentos de Marcuschi (2000) y de Bakbtin ([1929] 2002) acerca del agrupamiento de géneros. Aunque hay a discrepancias entre una y otra propuesta de concebir una constelación de géneros, es posible establecer un punto consensual entre esos estudiosos, en la medida en que ambos resaltan las tendencias de los géneros a las variaciones y a las transmutaciones. Los efectos de ese análisis permiten la conclusión de que un estudio que quiera emprender la caracterización de una constelación de géneros debe estructurarse a partir de tres ejes temáticos fundamentales: la(s) esfera (s) de comunicación en que tales géneros se ambientan; los rastros dejados durante su proceso de formación y los propósitos comunicativos atendidos por cada género dentro de la constelación.

Palabras-clave: Constelación de géneros. Esfera de comunicación. Transmutación. Propósito comunicativo. 